\title{
Potensi Emisi Gas Rumah Kaca pada Boezem Morokrembangan
}

\author{
Tanjung Mega Dwi Puspita dan Bieby Voijant Tangahu \\ Departemen Teknik Lingkungan, Fakultas Teknik Sipil Lingkungan dan Kebumian, Institut Teknologi \\ Sepuluh Nopember (ITS) \\ e-mail:bieby2003@gmail.com
}

\begin{abstract}
Abstrak-Boezem Morokrembangan merupakan salah satu Boezem terbesar di Kota Surabaya yang terletak di Kecamatan Krembangan di wilayah Surabaya bagian Utara. Air influen Boezem Morokrembangan bagian selatan berasal dari Sungai Greges dan Purwodadi. Besarnya kapasitas tampungan air Boezem Morokrembangan menyebabkan akumulasi bahan organik akibat air limbah domestik yang berasal dari Sungai Greges dan Sungai Purwodadi. Proses degradasi bahan organik secara anaerobik pada Boezem Morokrembangan menghasilkan gas rumah kaca yaitu $\mathrm{CO}_{2}$ dan $\mathrm{CH}_{4}$. Penelitian ini dilakukan dalam skala lapangan dan laboratorium. Data primer untuk penelitian lapangan yaitu data debit Boezem Morokrembangan. Pada penelitian laboratorium data primer diambil dari analisa parameter kualitas air yaitu BOD, COD, MLSS, MLVSS. Data sekunder yang digunakan meliputi data dimensi Boezem Morokrembangan. Prakiraan emisi $\mathrm{CO}_{2}$ dan $\mathrm{CH}_{4}$ pada Boezem Morokrembangan berdasarkan model persamaan dari US. EPA tahun 2010. Hasil penelitian menunjukkan Boezem Morokrembangan menghasilkan produksi gas $\mathrm{CO}_{2}$ sebesar 5,83 ton $\mathrm{CO}_{2} /$ hari sedangkan gas $\mathrm{CH}_{4}$ sebesar 2,301 ton $\mathrm{CH}_{4} /$ hari.
\end{abstract}

Kata Kunci-Bahan organik, Boezem Morokrembangan, Emisi gas rumah kaca, Gas $\mathrm{CH}_{4}$ dan $\mathrm{CO}_{2}$.

\section{PENDAHULUAN}

$\mathrm{M}$ ENINGKATNYA jumlah penduduk perkotaan memiliki pengaruh terhadap volume air limbah yang dihasilkan terutama air limbah domestik. Air limbah domestik mengandung bahan organik, anorganik, bakteri patogen, dan logam berat [1]. Saat ini, sebagian besar air limbah domestik perkotaan dibuang langsung ke saluran drainase dan badan air permukaan tanpa diolah terlebih dahulu. Saluran drainase memiliki fungsi ganda yaitu baik sebagai penampung air hujan, maupun mengalirkan air limbah domestik. Bahan pencemar dalam air limbah domestik ini mempunyai andil yang besar dalam menyumbang beban pencemar di badan air sehingga dapat meningkatkan rasio beban pencemar dalam ekosistem perairan [2]. Air limbah domestik perkotaan yang dibuang ke badan air dapat bermuara pada suatu embung (boezem) sebelum dialirkan ke laut. Salah satu boezem terbesar di Kota Surabaya adalah Boezem Morokrembangan. Saluran yang bermuara ke Boezem Morokrembangan bagian selatan meliputi saluran dari Sungai Greges dan Sungai Purwodadi. Nilai Chemical Oxygen Demand (COD) pada sampel air mencapai kisaran antara 33,74$104,98 \mathrm{mg} / \mathrm{L}$ [3]. Adanya kandungan bahan pencemar yang terdapat di air Boezem Morokrembangan menyebabkan terjadinya proses penguraian (degradasi) bahan pencemar yang dapat terjadi secara anaerobik. Proses degradasi anaerobik dapat mengahasilkan gas rumah kaca yaitu Gas $\mathrm{CH}_{4}$ dan $\mathrm{CO}_{2}$. Berdasarkan berkembangnya informasi tentang perubahan iklim global dan emisi gas rumah kaca, diperlukan mengkaji potensi emisi gas rumah kaca di Boezem Morokrembangan Selain itu, mengingat bahwa belum adanya data dan informasi mengenai prediksi emisi gas rumah kaca khusunya $\mathrm{CH}_{4}$ dan $\mathrm{CO}_{2}$ yang ada di Boezem Morokrembangan untuk melaksanakan upaya mitigasi dan strategi reduksi emisi yang dapat diimplementasikan. Dalam penelitian ini menilai bahwa kandungan zat organik dalam air limbah domestik yang terakumulasi di Boezem Morokrembangan mempengaruhi besarnya emisi gas $\mathrm{CH}_{4}$ dan $\mathrm{CO}_{2}$ ke atmosfer.

\section{METODE PENELITIAN}

\section{A. Ide Penelitian}

Ide penelitian ini berasal dari adanya bahan organik pada air Boezem Morokrembangan yang akan mengalami proses biodegradasi dan menghasilkan emisi gas rumah kaca yaitu gas metana $\left(\mathrm{CH}_{4}\right)$ dan gas karbon dioksida $\left(\mathrm{CO}_{2}\right)$. Dari permasalahan tersebut, diperlukan penelitian mengenai besarnya potensi emisi gas rumah kaca. Dengan demikian dapat dilakukan upaya untuk mereduksi emisi gas rumah kaca pada Boezem Morokrembangan.

\section{B. Studi Literatur}

Studi literatur dilakukan dengan tujuan untuk mendapatkan dasar teori yang kuat yang berkaitan dengan penelitian ini, sehingga dapat dijadikan acuan dalam melaksanakan kegiatan penelitian. Studi literatur dilakukan dengan mencari bahanbahan yang menunjang penelitian dari sumber-sumber yang ada. Sumber literatur meliputi text book, modul, jurnal/artikel ilmiah, laporan penelitian, tugas akhir, dan tesis terdahulu yang berhubungan dengan penelitian. Dalam penelitian ini dilakukan studi literatur tentang Boezem Morokrembangan, emisi gas rumah kaca, emisi gas rumah kaca pada pengolahan air limbah, estimasi emisi gas rumah kaca pada pengolahan air limbah.

\section{Pengumpulan Data}

Data primer yang dibutuhkan dalam penelitian ini diperoleh dari hasil pengamatan dan pengukuran di lokasi studi serta hasil analis is laboratorium. Pengukuran di lokasi studi meliputi pengukuran debit air inlet dan outlet Boezem Morokrembangan 
bagian selatan. Analisis laboratorium dalam penelitian ini meliputi parameter BOD, COD, MLSS, MLVSS. Sedangkan pengumpulan data sekunder meliputi gambaran umum, dimensi, dan debit Boezem Morokrembangan.

\section{Pelaksanaan Penelitian}

Pelaksanaan penelitian ini dilakukan dengan pengukuran debit dan pengambilan sampel air untuk analis is parameter kualitas air yang meliputi analis is BOD, COD, MLSS, MLVSS. Titik pengambilan sampel air dan pengukuran debit berada pada dua inlet Boezem yaitu Sungai Greges dan Purwodadi, serta outlet Boezem. Pengambilan sampel air untuk analisis BOD, COD, MLSS, dan MLVSS dan pengukuran debit dilaksanakan pada 3 waktu dalam sehari yaitu sekitar pukul 07.00-09.00, 11.00-13.00, dan 14.00-16.00 WIB untuk mengantisipasi fluktuasi debit pada setiap saluran dan dilaksanakan selama 7 hari untuk mendapatkan akurasi data yang baik. Pengukuran debit ini mengacu pada SNI 8066:2015. tentang tata cara pengukuran debit aliran sungai dan saluran terbuka menggunakan alat ukur arus dan pelampung. Pada penelitian ini digunakan alat untuk mengukur kecepatan aliran menggunakan pelampung. Prinsip pengukuran debit adalah mengukur kecepatan aliran, luas penampang basah, dan kedalaman.

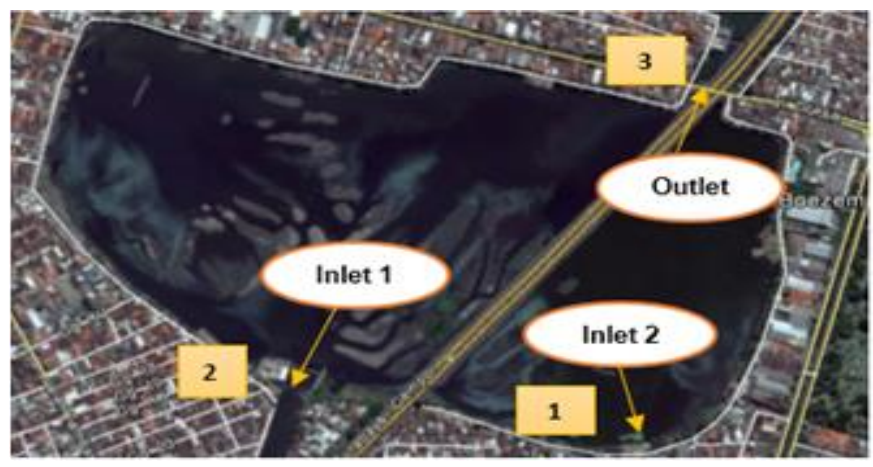

Gambar 1. Peta lokasi titik sampling BOD, COD, MLSS, MLVSS pada Boezem Morokrembangan.

\section{E. Pengolahan Data}

Dilakukan pengolahan data dari hasil penelitian lapangan dan laboratorium. Pengolahan data meliputi perhitungan emisi gas rumah kaca pada Boezem Morokrembangan diantaranya adalah gas $\mathrm{CO}_{2}$ dan $\mathrm{CH}_{4}$. Perhitungan emisi gas rumah kaca menggunakan pendekatan rumus untuk mengestimasi besarnya emisi gas rumah kaca pada unit pengolahan air limbah dari US. EPA tahun 2010 [4]. Emisi gas rumah kaca pada Boezem Morokrembangan dihitung di dua proses, yaitu pada proses biodegradasi air Boezem Morokrembangan dan pada proses digesting lumpur yang mengendap pada dasar Boezem Morokrembangan.

\section{HASIL DAN PEMBAHASAN}

\section{A. Hasil Penelitian Lapangan dan Analisis Parameter Kualitas Air}

Dari hasil penelitian lapangan yaitu pengukuran debit Boezem Morokrembangan didapatkan hasil berikut ini:
Debit rata-rata Sungai Purwodadi $=0,21 \mathrm{~m}^{3} /$ detik $=210$ Ldetik,

Debit rata-rata Sungai Greges $=2,30 \mathrm{~m}^{3} / \mathrm{detik}=2300 \mathrm{~L} / \mathrm{detik}$ Debit rata-rata outlet Boezem $=2,14 \mathrm{~m}^{3} /$ detik $=2140 \mathrm{~L} / \mathrm{detik}$

Pada penelitian laboratorium dilakukan analisis terhadap kualitas air yang masuk maupun yang keluar dari Boezem Morokrembangan. Didapatkan hasil analisis masing-masing sebagai berikut:

Tabel 1.

Hasil Analisis Paraneter Kualitas Air Sungai Purwodadi

\begin{tabular}{cc}
\hline \hline Parameter & Nilai rata-rata $(\mathrm{mg} / \mathrm{L})$ \\
\hline COD & 202,9 \\
BOD & 147,4 \\
MLSS & 101,5 \\
MLVSS & 80,4 \\
\hline \hline
\end{tabular}

Tabel 2 .

Hasil Analisis Paraneter Kualitas Air Sungai Greges

\begin{tabular}{cc}
\hline Parameter & Nilai rata-rata $(\mathrm{mg} / \mathrm{L})$ \\
\hline COD & 195,7 \\
BOD & 147,3 \\
MLSS & 116,2 \\
MLVSS & 91,2 \\
\hline \hline
\end{tabular}

Tabel 3 .

Hasil Analisis Paraneter Kualitas Air Outlet Boezem Morokrembangan

\begin{tabular}{cc}
\hline \hline Parameter & Nilai rata-rata $(\mathrm{mg} / \mathrm{L})$ \\
\hline COD & 147,6 \\
BOD & 106,5 \\
MLSS & 109,3 \\
MLVSS & 87,4 \\
\hline \hline
\end{tabular}

\section{B. Perhitungan Emisi Gas Rumah Kaca pada Boezem Morokrembangan}

Boezem Morokrembangan dapat digunakan sebagai reaktor alam untuk mengolah air limbah yang terakumulasi dari berbagai sumber pada catchment areanya. Boezem Morokrembangan sebagai kolam stabilisasi yang di dalamnya terdapat proses degradasi baik secara aerobik maupun anaerobik. Kedalaman Boezem Morokrembangan bagian selatan rata-rata adalah 3 meter [5]. Kondisi anaerobik dapat dicapai pada kedalaman kolam 2-5 meter [6]. Proses biodegradasi secara anaerobik terjadi pada zona endapan lumpur. Batas antara zona aerobik dan anaerobik pada Boezem Morokrembangan tidak tetap, hal ini bergantung pada beberapa faktor seperti kemampuan penetrasi cahaya matahari dan nilai Dissolved Oxygen (DO) dalam air yang dipengaruhi oleh turbulensi air akibat hempasan angin pada permukaan air. Zona anaerob akan semakin berada pada kedalaman air yang dangkal apabila tingkat kekeruhan air meningkat, hal ini mengakibatkan penetrasi cahaya matahari ke dalam air menjadi terhambat. Selain itu pada saat bersamaan kecepatan angin rendah. Sehingga pengadukan alami tidak dapat terjadi secara optimum pada ekosistem perairan boezem.

Pengolahan air limbah jika terjadi dalam kondisi anaerobik dapat menghasilkan emisi gas rumah kaca yaitu gas $\mathrm{CH}_{4}$ dan $\mathrm{CO}_{2}$. Pada proses pengolahan air limbah secara anaerobik, 
banyaknya bahan organik diubah menjadi biomassa atau dikonversikan menjadi $\mathrm{CH}_{4}$ dan $\mathrm{CO}_{2}$. Fraksi biomassa dikonversikan menjadi $\mathrm{CH}_{4}$ dan $\mathrm{CO}_{2}$ melalui respirasi endogenous, sementara sumber lain dari emisi gas rumah kaca pada pengolahan air limbah adalah proses digester lumpur [7]. Dengan analisis demikian maka diperkirakan bahwa di dalam boezem terdapat proses digesting lumpur yang mengendap yang terjadi dalam kondisi anaerobik sehingga menghasilkan emisi $\mathrm{CH}_{4}$ dan $\mathrm{CO}_{2}$. Pada fase liquid dipertimbangkan pada perhitungan emisi gas rumah kaca pada Boezem Morokrembangan, karena fase liquid juga ada dalam kondisi anaerobik sehingga proses degradasi zat organik menimbulkan emisi gas rumah kaca. Perhitungan emisi gas rumah kaca pada Boezem Morokrembangan menggunakan parameter BOD. Pada limbah cair domestik, karakteristik yang menentukan besarnya gas $\mathrm{CH}_{4}$ yang terbentuk selama proses degradasi komponen organik/karbon yang terdapat pada limbah adalah angka BOD [8].

Sebelum menghitung emisi gas rumah kaca, maka dilakukan perhitungan total konsentrasi bahan pencemar yang masuk pada Boezem Morokrembangan bagian selatan $\left(\mathrm{C}_{0}\right)$ dari Sungai Purwodadi dan Sungai Greges. Perhitungan ini digunakan untuk mengetahui besar beban organik dari air limbah yang masuk ke dalam Boezem Morokrembangan bagian selatan yang akan mengalami proses biodegradasi dan menghasilkan gas rumah kaca. Dengan demikian perhitungan total konsentrasi bahan pencemar yang masuk pada Boezem Morokrembangan bagian selatan dapat dihitung melalui perhitungan berikut ini:

Rata-rata debit Sungai Purwodadi $\left(\mathrm{Q}_{1}\right)=0,21 \mathrm{~m}^{3} /$ detik $=210$ Udetik

Rata-rata debit Sungai Greges $\left(\mathrm{Q}_{2}\right)=2,30 \mathrm{~m}^{3} /$ detik $=2300$ Udetik

Rata-rata konsentrasi BOD Sungai Purwodadi $\left(\mathrm{C}_{1}\right)=147,4 \mathrm{mg} / \mathrm{L}$

Rata-rata konsentrasi BOD Sungai Greges $\left(C_{2}\right)=147,3$ $\mathrm{mg} / \mathrm{L}$

Total konsentrasi bahan pencemar (Co)

$$
\begin{aligned}
\text { Co } & =\frac{Q 1 . C 1+Q 2 . C 2}{Q 1+Q 2} \\
& =\frac{210 \mathrm{~L} / \text { detik } x 147.4 \mathrm{mg} / \mathrm{L}+2300 \mathrm{~L} / \text { detik } x 147.3 \mathrm{mg} / \mathrm{L}}{210 \mathrm{~L} / \text { detik }+2300 \mathrm{~L} / \text { detik }} \\
& =147,3 \mathrm{mg} / \mathrm{L}
\end{aligned}
$$

Jika rata-rata konsentrasi BOD Outlet $\left(\mathrm{C}_{\mathrm{e}}\right)=106,5 \mathrm{mg} / \mathrm{L}$, maka presentase removal BOD di Boezem Morokrembangan bagian selatan adalah

$$
\begin{aligned}
\% R & =\frac{C o-C e}{C o} \times 100 \\
& =\frac{147, a \mathrm{mg} / \mathrm{L}-106,5 \mathrm{mg} / \mathrm{L}}{147_{\Perp} \mathrm{mg} / \mathrm{L}} \times 100 \\
& =27,7
\end{aligned}
$$

Diketahui bahwa proses biodegradasi bahan organik yang terjadi di dalam Boezem Morokrembangan mampu menurunkan konsentrasi bahan organik tersebut sebesar $27,7 \%$. Kemampuan boezem dalam menurunkan konsentrasi bahan pencemar relatif rendah. Rendahnya kemampuan Boezem dalam menurunkan konsentrasi bahan pencemar dipengaruhi oleh beberapa faktor salah satunya adalah adanya pendangkalan yang menyebabkan waktu tinggal hidraulik air di dalam Boezem menurun. Selain itu terjadinya penumpukan lumpur dan sampah pada daerah-daerah tertentu seperti intlet Boezem dapat menyebabkan kondisi septic dan meningkatkan kandungan zat padat pada zona stabilisasi. Untuk meningkatkan kinerja Boezem dapat dilakukan dengan pengerukan lumpur secara berkala dan pembersihan sampah pada titik-titik tertentu agar tidak mengganggu proses stabilisasi yang terdapat pada Boezem.

Selanjutnya dilakukan perhitungan emisi gas rumah kaca pada proses digesting lumpur dan fase liquid air limbah yang masuk pada Boezem Morokrembangan. Sebelum dilakukan perhitungan emisi gas rumah kaca, maka terlebih dahulu dilakukan perhitungan debit lumpur yang masuk ke dalam Boezem Morokrembangan menggunakan lumpur MLSS dan nilai yield (A) biomassa. MLSS menunjukkan konsentrasi padatan berupa padatan organik dan mikroorganisme yang terkandung di dalam reactor [9]. Nilai yield (A) biomassa merupakan rasio antara jumlah biomassa yang dihasilkan dan jumlah substrat yang digunakan dalam pengolahan secara biologis (gram biomassa/gram substrat) [10]. Perhitungan debit lumpur yang masuk (Qs) pada Boezem Morokrembangan bagian selatan jika diketahui

- Rata-rata [MLSS] Sungai Purwodadi $\left(\mathrm{C}_{1}\right)=101,50 \mathrm{mg} / \mathrm{L}$

Rata-rata [MLSS] Sungai Greges $\left(\mathrm{C}_{2}\right)=116,20 \mathrm{mg} / \mathrm{L}$

Rata-rata debit Sungai Purwodadi $\left(\mathrm{Q}_{1}\right)=0,21 \mathrm{~m}^{3} /$ detik $=210$ Ldetik

Rata-rata debit Sungai Greges $\left(\mathrm{Q}_{2}\right)=2,30 \mathrm{~m}^{3} /$ detik $=2300$ Ldetik

Maka debit lumpur dapat dihitung dengan menghitung massa lumpur yang masuk ke dalam Boezem Morokrembangan bagian selatan melalui perhitungan berikut ini

Massa lumpur

$=(C 1 \times Q 1)+(C 2 \times Q 2)$

$=(101,50 \mathrm{mg} / \mathrm{L} \times 210 \mathrm{~L} / \mathrm{dtk})+(116,20 \mathrm{mg} / \mathrm{L} \times 2300 \mathrm{~L} / \mathrm{dtk})$

$=288575 \mathrm{mg} /$ detik

$=0,289 \mathrm{~kg} /$ deti $\mathrm{k}$

Densitas lumpur tersuspensi adalah $990 \mathrm{~kg} / \mathrm{m}^{3}$ [11], sehingga dapat dihitung debit lumpur yang masuk (Qs) pada Boezem Morokrembangan bagian selatan.

$Q_{s}=\frac{\text { beban iumpur }}{\text { densitas iumpur }}=\frac{0,289 \frac{\mathrm{kg}}{\mathrm{drtik}} \mathrm{x} \text { a600 } \frac{\mathrm{datik}}{\mathrm{jam}}}{990 \mathrm{~kg} / \mathrm{m}^{3}}=1,05 \mathrm{~m}^{\mathrm{a}} \mathrm{jam}$

Setelah mengetahui debit lumpur, maka dapat dihitung nilai yield (A) biomassa dengan formulasi perhitungan berikut ini jika telah diketahui

Debit air limbah yang masuk ke dalam Boezem Morokrembangan (Qww)

Qww = Q Qungai Purwodadi $+Q_{\text {sungai Greges }}$

$=0,21 \mathrm{~m}^{3} /$ detik $+2,30 \mathrm{~m}^{3} /$ detik

$=2,51 \mathrm{~m}^{3} /$ detik $\times 3600 \mathrm{detik} / \mathrm{jam}$

$=9036 \mathrm{~m}^{3} / \mathrm{jam}$

- Konsentrasi total MLVSS yang masuk ke dalam Boezem Morokrembangan (MLVSS ${ }_{\mathrm{s}}$ )

$=\underline{\text { Qpurwodadi. [MLVSS] purwodadi }+ \text { Qgreges. }[\text { MLVSS] greges }}$

$=\frac{\text { Qpurwodadi }+ \text { Qgreges }}{\text { Qpere }}$

$=\frac{210 \mathrm{~L} / \text { detik } \cdot 80,40 \mathrm{mg} / \mathrm{L}+2300 \mathrm{~L} / \text { detik. } 91,20 \mathrm{mg} / \mathrm{L}}{210 \mathrm{~L} / \mathrm{det} / \mathrm{k}+2300 \mathrm{~L} / \text { detik }}$

$=90,3 \mathrm{mg} / \mathrm{L}$ 
- Total konsentrasi BOD yang masuk pada Boezem Morokrembangan $(\mathrm{OD})=147,3 \mathrm{mg} / \mathrm{L}$

- Efisiensi removal BOD $\left(\mathrm{EF}_{\mathrm{OD}}\right)=27,7 \%$

- Faktor koreksi karbon pada biomassa $\left(\mathrm{CF}_{\mathrm{s}}\right)=0,53 \mathrm{~g} \mathrm{C} / \mathrm{g}$ MLVSS

- Faktor konversi konsumsi $\mathrm{C}$ maksimum tiap unit oxygen demand $\left(\mathrm{CF}_{\mathrm{c}}\right)=12 / 32=0,375 \mathrm{~g} \mathrm{C} / \mathrm{g}$ oxygen demand

Maka nilai yield (A) biomassa dapat dihitung melalui perhitungan berikut ini:

$\lambda=\frac{Q_{S} \times M_{L V S S_{s}} \times C F_{s}}{Q_{\operatorname{lnv}} \times O D \times E F_{O D} \times C F_{c}}$

$$
\begin{aligned}
& =\frac{1,05 \frac{m^{3}}{\mathrm{jam}} \times 90,3 \frac{\mathrm{g}}{\mathrm{m}^{3}} \times 0,53 \mathrm{~g} \mathrm{C} / \mathrm{B} \text { BOD }}{9036 \frac{\mathrm{m}^{\mathrm{a}}}{\mathrm{jam}} \times 147,3 \frac{\mathrm{g}}{\mathrm{m}^{3}} \times 0,277 \times 0,375 \mathrm{~g} \mathrm{C} / \mathrm{g} \text { BOD }} \\
& =0,000363
\end{aligned}
$$

Gas rumah kaca yang diperhitungkan dalam penelitian ini adalah gas $\mathrm{CO}_{2}$ dan $\mathrm{CH}_{4}$ karena presentase produksi gas terbesar yang berasal proses pengolahan air limbah secara anaerobik adalah $\mathrm{CH}_{4}$ yaitu sebesar $70 \%$ dan yang kedua adalah $\mathrm{CO}_{2}$ sebesar 25\%-30\%, kemudian $\mathrm{N}_{2}, \mathrm{H}_{2}, \mathrm{H}_{2} \mathrm{~S}$, uap air, dan gas lain dalam jumlah yang kecil [12]. Gas $\mathrm{CO}_{2}$ dan $\mathrm{CH}_{4}$ merupakan gas rumah kaca, sehingga jika gas tersebut dalam jumlah yang besar teremisikan ke atmosfer maka akan menyebabkan efek rumah kaca yang berdampak pada pemanasan global.

Perhitungan emisi gas rumah kaca pada Boezem Morokrembangan menggunakan model pendekatan rumus menurut US.EPA tahun 2010. Dalam menghitung emisi gas rumah kaca digunakan nilai faktor yaitu Methane Correction Factor (MCF) yang merupakan nilai koreksi gas metan pada air limbah, dimana nilai tersebut menyatakan fraksi zat organik yang mampu terkonversi pada kondisi anaerobik dalam suatu unit pengolahan air limbah. Pada penelitian ini digunakan nilai MCF yaitu 0,8 bahwa nilai tersebut dapat digunakan untuk sistem pengolahan pada proses anaerobik, kolam fakultatif, dan pada proses digesting lumpur secara anaerobik.

Nilai faktor lain yang digunakan dalam perhitungan emisi gas rumah kaca ini adalah nilai faktor konversi gas metan $\left(\mathrm{CF}_{\mathrm{CH} 4}\right)$ dan faktor konversi gas karbondioksida $\left(\mathrm{CF}_{\mathrm{CO} 2}\right)$ yang menyatakan nilai produksi dari masing-masing gas per unit oxygen demand. Nilai $\mathrm{CF}_{\mathrm{CH} 4}$ adalah $0,5 \mathrm{~g} \mathrm{CH}_{4} / \mathrm{g}$ oxygen demand sedangkan nilai $\mathrm{CF}_{\mathrm{CO} 2}$ adalah $1,375 \mathrm{~g} \mathrm{CO}_{2} / \mathrm{g}$ oxygen demand. Kemudian nilai fraksi $\mathrm{CH}_{4}$ pada pembentukan biogas dinyatakan dengan $\mathrm{BG}_{\mathrm{CH} 4}$ yang mempunyai nilai default 0,65 . Perhitungan emisi gas rumah kaca fase liquid air limbah pada Boezem Morokrembangan bagian selatan dihitung dengan formulasi berikut ini

Emisi $\mathrm{CO}_{2}$

$=10^{-6} \times Q_{W W} \times O D \times E f f_{O D} \times C F_{C O 2} \times[(1-$

$\left.M C F_{W W} \times B G_{C H 4}\right)(1-\lambda)$

$=10^{-6} x 9036 \frac{m^{5}}{\mathrm{jam}} \times 147,3 \frac{\mathrm{g}}{\mathrm{m}^{3}} \times 0,277 \times 1,375 x[(1-0,8 \times 0,65)(1-0,000363)]$

$=0,243$ ton $\mathrm{CO}_{2} / \mathrm{jam}$

$\approx 5,832$ ton $\mathrm{CO}_{2} /$ hari

Emisi $\mathrm{CH}_{4}$

$=10^{-6} \times Q_{\text {WW }} \times O D \times E f_{O D} \times C F_{C H 4} \times\left[\left(M C F_{\text {WNV }} \times B G_{C H 4}\right)(1-\right.$

ג)

$$
\begin{aligned}
& =10^{-6} \times 9036 \frac{\mathrm{m}^{\mathrm{a}}}{\mathrm{jam}} \times 147,3 \frac{\mathrm{g}}{\mathrm{m}^{\mathrm{a}}} \times 0,277 \times 0,5 \times[(0,8 \times 0,65)(1-0,000363) \\
& =0,096 \text { ton } / \mathrm{jam} \\
& \approx 2,3 \text { ton } / \text { hari }
\end{aligned}
$$

Selanjutnya, menghitung emisi gas rumah kaca dalam proses digesting lumpur pada Boezem Morokrembangan bagian selatan menggunakan persamaan berikut ini

$$
\begin{aligned}
& \text { Emisi } \mathrm{CO}_{2} \\
& =10^{-6} \times Q_{s} \times \text { MLVSS } x C_{5} \times \frac{44}{12} x\left(1-M C F_{\text {IVW }} \times B G_{C H 4}\right) \\
& =10^{-6} x 1,05 \frac{m^{3}}{\text { jam }} x 90,3 \frac{g}{m^{3}} x 0,53 x \frac{44}{12} x(1-0,8 x 0,65) \\
& =0,000088 \text { ton } \mathrm{CO}_{2} / \mathrm{jam} \\
& \approx 0,00212 \text { ton } \mathrm{CO}_{2} / \text { hari } \\
& \mathrm{EmisiCH}_{=10^{-6}} \times Q_{s} \times \text { MLVSS } x \mathrm{CF}_{5} \times \frac{16}{12} \times\left(1-M C F_{\text {WW }} \times B G_{C H 4}\right) \\
& =10^{-6} \times 1,05 \frac{m^{3}}{\mathrm{jam}} x 90,3 \frac{g}{m^{3}} \times 0,53 \times \frac{16}{12} x(1-0,8 \times 0,65) \\
& =0,000032 \text { ton } \mathrm{CO}_{2} / \mathrm{Jam} \\
& \approx 0,00077 \text { ton } \mathrm{CO}_{2} / \text { hari }
\end{aligned}
$$

Proses digesting lumpur pada Boezem Morokrembangan bagian selatan dapat menghasilkan gas $\mathrm{CO}_{2}$ sebesar 0,00212 $\mathrm{CO}_{2} /$ hari dan gas $\mathrm{CH}_{4}$ sebesar 0,00077 ton $\mathrm{CH}_{4} /$ hari. Sehingga total gas rumah kaca yang diproduksi karena proses biodegradasi dalam Boezem Morokrembangan dapat dihitung dengan menambahkan jumlah gas $\mathrm{CO}_{2}$ dan $\mathrm{CH}_{4}$ yang dihasilkan pada fase liquid air limbah dan digesting lumpur menurut perhitungan berikut ini

Total laju produksi gas $\mathrm{CO}_{2}$ pada Boezem Morokrembangan

$=$ Emisi $\mathrm{CO}_{2}$ fase liquid + Emisi $\mathrm{CO}_{2}$ digesting lumpur

$=5,832$ ton $\mathrm{CO}_{2} /$ hari $+0,00212$ ton $\mathrm{CO}_{2} /$ hari

$=5,83$ ton $\mathrm{CO}_{2} /$ hari

Total laju produksi gas $\mathrm{CH}_{4}$ pada Boezem Morokrembangan

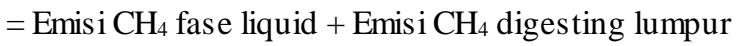

$=2,3$ ton $\mathrm{CH}_{4} /$ hari $+0,00077$ ton $\mathrm{CH}_{4} /$ hari

$=2,301$ ton $\mathrm{CH}_{4} /$ hari

Dari total gas yang diproduksi pada Boezem Morokrembangan dapat dilihat bahwa jumlah produksi gas cukup besar. Besarnya produksi gas ini disebabkan karena debit yang masuk pada Boezem Morokrembangan diperkirakan dalam keadaan debit puncak. Saat terjadi debit puncak maka bahan organik yang masuk ke dalam Boezem akan semakin besar, sehingga menyebabkan beban organik besar.

\section{KESIMPULAN}

Proses biodegradasi pada Boezem Morokrembangan yang terjadi dalam kondisi anaerobik menyebabkan emisi gas rumah kaca pada Boezem. Potensi gas rumah kaca pada Boezem Morokrembangan menunjukkan produksi gas $\mathrm{CO}_{2}$ sebesar 5,83 ton $\mathrm{CO}_{2} /$ hari dan gas $\mathrm{CH}_{4}$ sebesar 2,301 ton $\mathrm{CH}_{4} /$ hari.

\section{DAFTAR PUSTAKA}

A. F. Malisie, M. Prihandrijanti, and R. Otterpoh, "The Potential of Nutrient Reusse from A Source-separated 
Domestic Wastewater System In Indonesia - Case Study: Ecological Sanitation Pilot Plant In Surabaya," Water Sci. Technol., vol. 56, no. 5, pp. 141-148, 2007.

[2] L. Morris et al., "Municipal Wastewater Effluent Licensing: A Global Perspective and Recommendations for Best Practice," Sci. Total Environ., vol. 13, 2016.

[3] Hasriyani, "Studi Kinerja Boezem Morokrembangan pada Penurunan Kandungan Total Solid dan Zat Organik sebagai Permanganante Value (PV)," Surabaya, 2010.

[4] US.EPA, "Greenhouse Gas Emissions Estimation Methodologies for Biogenic Emissions from Selected Source Categories: Solid Waste Disposal, Waste Water Treatment, Ethanol Fermentation," 2010.

[5] R. Putri, D. Priyantoro, L. Prasetyorini, and H. Suprijanto, "Evaluasi Sistem Drainase Daerah Muara Boezem Utara Morokrembangan Surabaya," J. Tek. Pengair. Fak. Tek. Univ. Brawijaya, 2014.

[6] Al-Hashimi, M. Ali, Hussain, and H. Talee., "Stabilization Pond For Wastewater Treatment," Eur. Sci. J., vol. 9, no. 14,
2013.

[7] D. Gupta and S. Singh, "Greenhouse Gas Emissions from Wastewater Treatment Plants: A Case Study of Noida," $J$. Water Sustain., vol. 2, no. 2, pp. 131-139, 2012.

[8] IPCC, Guidelines for National Greehouse Gas Inventories. Washingt on D.C., 2006.

[9] F. Sari, R. Anissa, and A. Tuhuloula, "Perbandingan Limbah dan Lumpur Aktif Terhadap Pengaruh Sistem Aerasi ppada Pengolahan Limbah CPO," Konversi, vol. 2, no. 1, 2013.

[10] Metcalf and Eddy, Wastewater Engineering Treatment And Resource Recovery. 5th edition. New York: Mc Graw Hill, 2014.

[11] Satwika, "Teknis Penanganan Sedimen Secara Kuratif pada Bagian Selatan Boezem Morokrembangan,” IT S, 2012.

[12] A. Amiri, J. Tsutsumi, and R. Nakamatsu, "Energy from Domestic Wastewater and Recovering The Potential Energy of Sewage Sludge," J. Energy Technol. Policy, vol. 5, no. 12, 2015. 